\title{
Processos constitutivos das políticas educacionais no âmbito municipal: a pesquisa-ação colaborativa como postura epistemológica, metodológica e política
}

\section{Constitutive processes of the education policies in the municipal context: collaborative action research as epistemological, methodological and political}

posture

\section{Los procesos constitutivos de las políticas educativas en el ámbito municipal: la investigación- acción colaborativa como postura epistemológica, metodológica y política}

Dirléia Fanfa Sarmento* Cledes Antonio Casagrande*

\begin{abstract}
Resumo: Este texto analisa os processos constitutivos das políticas educacionais municipais, enfatizando as contribuições da pesquisa-ação colaborativa nesses processos como postura que alimenta o compromisso político, o pensamento crítico e as relações cooperativas para a constituição de comunidades de aprendizagem. Este artigo articula as reflexões oriundas de uma postura meta-analítica do próprio processo investigativo com a constituição das políticas educacionais em tela, tendo como protagonistas os profissionais da educação que atuam na Secretaria de Educação. Os achados, decorrentes da análise do conteúdo de documentos, dos registros de observações, de encontros formativos no Diário de Campo e das entrevistas, sinalizam que os impactos derivados da pesquisa-ação não são imediatos, mas expectáveis com o decorrer do tempo - típico de grupos que partilham e constroem cumplicidades científicas, epistemológicas e pedagógicas.
\end{abstract}

Palavras-chave: Políticas Educacionais. Pesquisa-ação colaborativa. Princípios epistemológicos.

\footnotetext{
*Professora do Centro Universitário La Salle de Canoas (Unilasalle). E-mail: <fanfa@unilasalle.edu.br $>$

** Pós-Doutorando em Educação do Centro Universitário La Salle de Canoas (Unilasalle). E-mail: <cledes. casagrande@unilasalle.edu.br>
} 


\begin{abstract}
This text analyses the constitutive processes of the municipal education policies, highlighting the contributions from the collaborative action research in these processes as posture which feeds the political commitment, the critical thought and the cooperative relations for the constitution of learning communities. This article articulates the reflection from a meta-analytical posture of the investigative process itself with the composition of the education policies brought into focus, having as protagonists the education professionals who work in the Board of Education. The findings, from the analysis of the documents content; the reports of observations, of the formative meetings in the Field Diary and of the interviews, signalize that the impacts derived from the action research are not immediate, but expectable in the course of time - typical of groups which share and build scientific, epistemological and pedagogical complicities.
\end{abstract}

Keywords: Education policies. Collaborative action research. Epistemological principles.

Resumen: Este texto analiza los procesos constitutivos de las políticas educativas municipales, enfatizando las contribuciones de la investigación-acción colaborativa en esos procesos como una postura que alimenta el compromiso político, el pensamiento crítico y las relaciones cooperativas para la constitución de comunidades de aprendizaje. Este texto articula las reflexiones derivadas de una postura meta-analítica del propio proceso investigativo con la constitución de las políticas educativas presentadas, teniendo como protagonistas a los profesionales de la educación que actúan en la Secretaria de Educación. Los hallazgos, provenientes del análisis del contenido de documentos, de los registros de observaciones, de los encuentros formativos en el Diario del Campo y de entrevistas, señalan que los impactos provenientes de la investigación-acción no son inmediatos, pero esperables con el paso del tiempo-típico de grupos que comparten y construyen complicidades científicas, epistemológicas y pedagógicas.

Palabras claves: Políticas Educativas. Investigación-acción colaborativa. Principios epistemológicos.

\title{
Introdução
}

Este artigo tem como objetivo analisar os processos constitutivos das políticas educacionais no âmbito municipal, enfatizando as contribuições da pesquisa-ação colaborativa nesse processo, na qualidade de postura epistemológica e metodológica que alimenta o compromisso político, o pensamento crítico e as relações cooperativas para a constituição de comunidades de aprendizagem.

As reflexões aqui delineadas partem de um conjunto de ações desenvolvidas junto à Secretaria Municipal de Educação de um município situado na 
Região Metropolitana de Porto Alegre, contemplando ações de ensino, pesquisa e extensão. Dentre tais ações, destacamos a construção de uma Política Pública Municipal de Valorização e Qualificação dos Profissionais da Educação, a qual conferiu autenticidade e legitimou a constituição de uma plataforma formativa direcionada aos profissionais que atuam na rede pública municipal.

No presente texto, partimos da seguinte situação problema: as políticas educacionais de um sistema educacional municipal podem ser constituídas desde a perspectiva da pesquisa-ação colaborativa? Quais pressupostos teóricos necessitam fundamentar esse tipo de ação prática? Quais os ganhos possíveis, em termos de aprendizagem e de conhecimento, dos participantes de uma pesquisa-ação colaborativa em políticas educacionais?

No intuito de discorrer sobre a situação problemática apresentada e tendo presente o objetivo que nos propomos, este texto está estruturado em três seções. Na primeira seção, contextualizamos a proposta da pesquisa-ação colaborativa por meio de um exercício meta-analítico, identificando o campo, o horizonte teórico e o enfoque espistemológico a partir do qual estruturamos a referida investigação. $\mathrm{Na}$ segunda seção, discorremos sobre o estatuto teórico-prático da pesquisa-ação colaborativa desenvolvida, bem como explicitamos os elementos que caracterizam a realidade pesquisada. $\mathrm{Na}$ seção seguinte, apresentamos ideias centrais oriundas da interpretação e da análise dos dados, refletindo sobre os avanços, os desafios e as lacunas encontradas no decorrer da pesquisa. Finalmente, tecemos algumas considerações evidenciando os principais achados do estudo e sinalizando questões para a sua continuidade.

\section{Contextualizando a proposta de uma pesquisa-ação colaborativa: algumas considerações premilinares}

A pesquisa-ação colaborativa consiste, no entender de Carr e Kemmis (1988), em uma abordagem pautada pelo princípio da investigação-ação crítica. Nela, o investigador opta por uma posição espistemológica que leva em conta que seu olhar é "para a educação e não sobre a educação", articulando teoria e prática, de forma crítica, em um processo de ação-investigação "que parte da realidade e contribui com ela" (TELLO, 2012a, p. 295), visando à melhoria dos processos e da realidade na qual a pesquisa ação é desenvolvida.

Ao focalizar os processos constitutivos das políticas educacionais, entendemos que tanto os modos de condução dos processos quanto os resultados derivados deles refletem e traduzem concepções epistemológicas que nem sempre estão evidentes. Igualmente, quando o pesquisador faz uma opção teórico-metodológica para investigar tais processos, também não o faz de modo imune, neutro e descolado dessas concepções. Ele carrega consigo suas crenças, 
seus valores, suas concepções e seus posicionamentos acerca do conhecimento, da relação entre sujeito e objeto, da educação, da teoria e da prática, do seu próprio papel como pesquisador, da função da pesquisa na mudança, na constituição e na tranformação dos sujeitos e de suas realidades.

Com base no exposto, articulamos as reflexões aqui explicitadas a partir de uma postura meta-analítica, buscando contemplar uma "vigilância epistemológica" (TELLO 2012a, 2012b) acerca do processo investigativo ${ }^{1}$, bem como em relação ao processo de constituição das políticas em tela. Nessa tentativa meta-analítica, pautada sobre a díade processo investigativo e processo constitutivo, na qualidade de pesquisadores e de sujeitos partícipes de ambos os processos, tencionamos preservar uma posição alicerçada em uma convicção de que toda investigação é circunstanciada, não existindo neutralidade na ciência e, tampouco, ausência de referenciais ou de pré-conceitos por parte dos envolvidos. Nesse sentido, entendemos que é necessária "uma prestação de contas históricoconceitual" (GADAMER, 2007, p. 11) acerca das teoriais, das espistemologias e das metodologias utilizadas. Ao prestar contas da pré-conceitualidade para o nosso fazer investigativo, temos consciência de que estamos envolvidos em um mundo da vida, que " $[. .$.$] constitui um horizonte e, ao mesmo tempo, oferece um$ acervo de evidências culturais do qual os participantes da comunicação tiram, em seus esforços de interpretação, padrões exegéticos consentidos" (HABERMAS, 2002a, p. 416-417), bem como nos permite estabelecer entendimentos, compartilhar perspectivas e encontrar coletivamente soluções aos problemas com os quais nos defrontamos.

Entendemos que o campo da educação, contexto das políticas educacionais, não está alheio às tendências e aos confrontos teóricos. Tais tendências e confrontos configuram-se, de modo geral, a partir de uma intrincada relação entre os planos histórico-social, cultural e econômico de uma determinada época, dos planos pessoais e sociais dos diversos atores e profissionais da educação, bem como do plano das tradições e das práticas educativas já implementadas na história. Desde essa perspectiva, alinhamo-nos à afirmação de Charlot (2006) de que o campo da educação é um campo mestiço, visto que a educação é uma área na qual circulam conhecimentos, práticas e políticas distintas.

Delimita-se assim uma primeira definição da disciplina educação ou ciências da educação: é um campo de saber fundamentalmente mestiço, em que se cruzam, se interpelam e, por vezes, se fecundam, de um lado, conhecimentos,

\footnotetext{
${ }^{1}$ Compartilhamos da perspectiva de Tello (2012a, 2012b) sobre a necessidade de que, no campo das políticas educativas, as intervenções e as pesquisas sejam realizadas sob o signo de uma vigilância epistemológica. Essa vigilância implica uma atitude prática, por parte do pesquisador, que leve em consideração a explicitação dos pressupostos prévios a partir dos quais a investigação é realizada, bem como a existência de um sistema cruzado de certificação, que envolva a explicitação do posicionamento epistemológico, da perspectiva epistemológica e do enfoque epistemetodológico.
} 
conceitos e métodos originários de campos disciplinares múltiplos, e, de outro lado, saberes, práticas, fins éticos e políticos. O que define a especificidade da disciplina é essa mestiçagem, essa circulação. (CHARLOT, 2006, p. 9).

Assim, partimos do pressuposto de que tanto a educação quanto as políticas relacionadas a ela precisam ser compreendidas em sua complexidade e especificidade. Necessitam ser analisadas sob suas diversas matizes, o que requer um olhar inter, multi e transdisciplinar. Se, por um lado, a contribuição de diferentes áreas - traduzidas em teorias, princípios e práticas -, pode favorecer a problematização; por outro, dependendo da incursão e das interfaces realizadas, pode acentuar as discrepâncias de um campo do saber que, por si só, pode ser considerado controverso.

Além disso, toda ação, pesquisa ou política educativa possui íntima relação com o contexto histórico-social no qual se insere e no qual é focada. Com isso, estamos afirmando que falar em processos constitutivos de políticas educacionais implica, necessariamente, dar vozes ao contexto conceitual a partir do qual se fala e se age: é chave conhecer de onde falamos e agimos (BOURDIEU, 2004). Nesse cenário, não podemos deixar de considerar que vivemos em uma sociedade marcada pela pluralidade e pelo relativismo; e que esses fenômenos possuem influência direta nas políticas e nas práticas educacionais atuais, ou, se preferirmos, eles provocam consequências epistemológicas e práticas na educação. A sociedade contemporânea, em oposição ao pensamento e à estruturação conceitual da sociedade moderna, permite que entrem em cena múltiplas possibilidades de fundamentação do conhecer e do agir. Agora, a unidade da razão passa a ser entendida em sua pluralidade de vozes, e a ciência é convidada a revisar seu estatuto de legitimidade, seu modus operandi e seus efeitos. Ocorre, também, um rompimento epistemológico com o conceito de verdade universal, passando esta a ser entendida como uma construção histórica, interpretada e falseável. Nesse sentido, em consonância com a visão de Habermas:

As componentes do mundo da vida - a cultura, a sociedade, e as estruturas da personalidade - formam contextos de significado complexos que se comunicam entre si embora estejam incorporados em substratos diferentes. $\mathrm{O}$ conhecimento cultural materializa-se em formas simbólicas - em objetos utilitários e tecnologias, em palavras e teorias, em livros e documentos, etc. - tal como o faz nas ações. Quanto à sociedade, toma forma nas ordens institucionais, nas normas legais ou nas redes de práticas e costumes normativamente regulados. (HABERMAS, 2002b, p. 141).

Sob o olhar que o mundo é estruturado simbolicamente, os conceitos oriundos da cultura, da sociedade e da identidade pessoal são (re)construídos mediante processos dialéticos e constantes entre os seres humanos e as 
instituições sociais, implicando um comprometimento vital desses mesmos seres. Então, a relação do ser humano com o mundo, espaço de configuração de si - na autoreconstrução da própria identidade e das estruturas de significado do próprio mundo -, consiste em uma relação eminentemente simbólica e mediada pela linguagem (HABERMAS, 2002a).

É oportuno destacar que as políticas educacionais têm se constituído, cada vez mais, em temática de investigações as quais são desenvolvidas a partir de diversos enfoques teórico-metodológicos e respectivos pressupostos epistemológicos que os fundamentam, conforme apontam Azevedo e Aguiar (2001). Destacamos, nesse cenário, as valiosas contribuições de Telo (2012a, 2012b) sobre o estatuto epistemológico das políticas educativas na América Latina, especialmente no que se refere à defesa desse campo como um espaço de investigação no qual é possível produzir, divulgar e aplicar conhecimento.

\section{A pesquisa-ação colaborativa: um olhar da teoria à prática}

A pesquisa-ação tem suas origens nos trabalhos do psicólogo social Kurt Lewin, na década de 1940, o qual preconizou a importância de um modelo investigativo que contemplasse o envolvimento entre o pesquisador e os sujeitos pesquisados, promovendo a participação e o comprometimento das pessoas em questões sociais. A partir da década de 1960, várias leituras surgem acerca da pesquisa-ação, especialmente no que se refere à questão da ação/intervenção no tecido social, algumas enfatizando a dimensão explicativa experimental e outras a fenomenológica ou dialética (MIRANDA; RESENDE, 2006). A compreensão sobre o conceito da pesquisa-ação requer, de certa forma, a reflexão sobre a relação entre teoria e prática, ganhando a ação/intervenção centralidade nessa modalidade de pesquisa. No dizer de Miranda e Resende:

Tratar-se-ia, assim, de uma pesquisa que articula a relação entre teoria e prática no processo mesmo de construção do conhecimento, ou seja, a dimensão da prática que é constitutiva da educação - seria fonte lugar privilegiado da pesquisa. Além disso, a própria investigação se converteria em ação, em intervenção social, possibilitando ao pesquisador uma atuação efetiva sobre a realidade estudada. Reflexão e prática, ação e pensamento, pólos antes contrapostos, agora seriam acolhidos em uma modalidade de pesquisa que considera a intervenção social na prática como seu princípio e seu fim último. (MIRANDA; RESENDE, 2006, p. 514).

No entender de Kemmis e McTaggart,

A pesquisa-ação é uma forma de indagação introspectiva coletiva empreendida pelos participantes em situações sociais com objetivo de melhorar a racionalidade e a justiça de suas práticas sociais e educativas, assim 
com sua compreensão destas práticas e das situações em que estas têm lugar. (KEMMIS; MCTAGGART, 1992, p. 9).

Realizar pesquisa-ação, segundo os autores supracitados, implica planejamento, ação, observação, reflexão cuidadosa, sistemática e regular para além da observação da vida cotidiana. Para eles, ao pesquisador envolvido com pesquisa-ação competem quatro tarefas básicas, a saber: o plano é ação organizada e antecipa a ação; a ação é deliberada e controlada; a observação tem função de documentar os efeitos da ação criticamente informada; e a reflexão rememora a ação tal como ficou registrada pela observação. Franco, M. A. S. (2005) apresenta três dimensões que, comumente, mobilizam os pesquisadores a optar pela pesquisa-ação:

a. quando a busca de transformação é solicitada pelo grupo de referência à equipe de pesquisadores, a pesquisa tem sido conceituada como pesquisaação colaborativa, em que a função do pesquisador será a de fazer parte e cientificizar um processo de mudança anteriormente desencadeado pelos sujeitos do grupo;

b. se essa transformação é percebida como necessária a partir dos trabalhos iniciais do pesquisador com o grupo, decorrente de um processo que valoriza a construção cognitiva da experiência, sustentada por reflexão crítica coletiva, com vistas à emancipação dos sujeitos e das condições que o coletivo considera opressivas, essa pesquisa vai assumindo o caráter de criticidade e, então, tem se utilizado a conceituação de pesquisa-ação crítica;

c. se, ao contrário, a transformação é previamente planejada, sem a participação dos sujeitos, e apenas o pesquisador acompanhará os efeitos e avaliará os resultados de sua aplicação, essa pesquisa perde o qualificativo de pesquisa-ação crítica, podendo ser denominada de pesquisa-ação estratégica. (FRANCO, M. A. S., 2005, p. 485-486).

No caso de nosso estudo, é possível destacar, de forma articulada, as duas primeiras dimensões apresentadas por Franco como propulsoras da investigação sobre os processos constitutivos da Política de Valorização e Qualificação dos Profissionais da Educação no município, conforme já referido anteriormente. Corroborando a posição de Franco, M. A. S. (2005), entendemos que:

Se alguém opta por trabalhar com pesquisa-ação, por certo tem a convicção de que a pesquisa e ação podem e devem caminhar juntas quando se pretende a transformação da prática. No entanto, a direção, o sentido e a intencionalidade dessa transformação serão o eixo da caracterização da abordagem da pesquisa-ação. (FRANCO, M. A. S., 2005, p. 485).

Zeichner e Diniz-Pereira (2005) indicam as seguintes contribuições da pesquisa-ação, tendo em vista a transformação social de uma prática: 
[...] 1. melhorar a formação profissional e, por conseguinte, propiciar serviços sociais (educação, saúde etc.) de melhor qualidade; 2. potencializar o controle que esses profissionais passam a exercer sobre o conhecimento ou a teoria que orienta os seus trabalhos; 3. influenciar as mudanças institucionais nos locais de trabalho desses profissionais (escolas, hospitais, agências de serviço social etc.); 4. contribuir para que as sociedades tornem-se mais democráticas e mais decentes para todos (ou seja, sua ligação com temas de reprodução ou de transformação social). (ZEICHNER; DINIZ-PEREIRA, 2005, p. 64-65).

Entretanto, é necessário ter presente a crítica feita por Miranda e Resende (2006) quando as autoras discorrem sobre o risco do praticismo que pode advir do posicionamento epistemológico que fundamenta a pesquisa-ação. As pesquisadoras alertam que

[...] deve-se insistir no risco de fazer com que a pesquisa-ação seja convertida em estratégia de políticas públicas com a finalidade de imprimir reformas no campo da retórica e da ação do professor, quando então a sua discussão epistemológica e conceitual se transfere para normalizações instituidoras da prática docente. A instituição da pesquisa como prática comum e generalizada aos professores ou às escolas desconsidera que ela requer suporte institucional e acadêmico adequado, condições de trabalho compatíveis, além da disposição e do interesse dos docentes. Sem essas condições, pode-se alimentar uma retórica reformista que institui o imperativo de que o professor assuma sozinho a decisão e o risco de se contrapor a uma realidade que não dá sinais de pretender se transformar. (MIRANDA; RESENDE, 2006, p. 517).

Partimos de uma compreensão de que o cerne da pesquisa-ação está no fato de que não basta apenas compreender, mas é preciso, a partir dessa compreensão, contribuir para a transformação tanto dos sujeitos quanto de suas realidades e contextos.

\section{Contexto do locus e da emergência da temática investigativa}

O locus investigativo é a Rede Pública Munipal de Ensino de uma cidade situada na Região Metropolitana de Porto Alegre. Tal munícipio tem se constituído em locus investigativo de nosso grupo de pesquisa, desde o ano de 2006, no que se refere à área educacional, contemplando-se tanto os profissionais que atuam no âmbito da Secretaria Municipal de Educação quanto aqueles dos contextos educativos das escolas pertencentes a essa Rede. Dentre os estudos, destacamos: A transição do Ensino Fundamental para nove anos (financiada pelo CNPq); a Alfabetização nos anos iniciais do Ensino Fundamental e formação de professores (financiada pelo Observatório da Educação INEP/CAPES); Formação de professores, intervenção pedagógica e avaliação da qualidade da educação (financiada pela Prefeitura Municipal). 
Reiteramos a importância da relação entre a Instituição de Ensino Superior, locus privilegiado de construção do conhecimento e de formação, e os sistemas de ensino presentes no entorno onde ela exerce sua ação educativa. Ao assumir uma responsabilidade conjunta, consolidam-se comunidades de aprendizagem e ações colaborativas que viabilizam, por um lado, apoio aos profissionais da educação básica, e, por outro, seus saberes, suas práticas e suas reflexões configuram-se em retro-alimentação para as pesquisas desenvolvidas no espaço acadêmico. Nessa relação dialógica e colaborativa, a produção do conhecimento pode contribuir sobremaneira para a excelência educacional. Contudo, tal postura, por parte dos pesquisadores, requer um olhar diferenciado sobre seu próprio status de pesquisador, estando vários deles sentindo-se "[...] cada vez mais desconfortáveis em sua posição de somente estudar o trabalho dos outros e [...] cada vez mais aborrecidos em estar relevando falhas de escolas e professores, obtendo com isso apenas vantagens em suas carreiras acadêmicas" (ZEICHNER, 1998, p. 210). Nessa linha reflexiva, conforme salienta Zeichner:

Também as estruturas das universidades, que desencorajam o engajamento dos professores na discussão sobre a relevância de suas pesquisas ou no trabalho colaborativo, precisam ser mudadas. Concordo que estas e outras mudanças sejam necessárias para verdadeiramente eliminar a exploração de professores por pesquisadores acadêmicos, mas também penso que muito pode ser feito para aumentar o padrão ético e o nível de democracia na pesquisa acadêmica, auxiliando a valorizá-la nas escolas. (ZEICHNER, 1998, p. 210).

Concluindo sua reflexão, o autor supracitado afirma que:

[...] é preciso olhar muito de perto para o caráter e para a qualidade das colaborações em pesquisas para se determinar se há realmente alguma mudança nos padrões usuais dominantes na academia. Pesquisa colaborativa é um importante caminho para superar a divisão entre acadêmicos e professores, mas não é qualquer pesquisa colaborativa que faz isso. (ZEICHNER, 1998, p. 214).

A nossa inserção como pesquisadores nesse locus investigativo e os achados dos estudos realizados viabilizaram o processo de reelaboração das estratégias de ação, garantindo, dessa forma, o movimento espiralado próprio da metodologia da pesquisa-ação. Assim, na sequência da segunda fase da pesquisa, focamos na tematização dos processos constitutivos das Políticas Educacionais Municipais oportunizando-se, dessa forma, novos espaços e tempos que foram dedicados à investigação de tal temática. 


\section{Espaço temporal do estudo}

Desde o ano de 2006, temos realizado pesquisas na área educacional, tendo como lócus investigativo o município em tela. Dentre os achados dessas pesquisas, ficou evidenciado a transversalização das políticas educacionais no modus operandi, tanto no âmbito da Secretaria de Educação quanto no contexto das escolas. A partir do ano de 2009, quando a atual gestão municipal assumiu o governo, os estudos intensificaram-se focando a construção coletiva de uma identidade educacional do município, a valorização e a qualificação dos profissionais da educação, e a revitalização de dispositivos legais como o Plano Municipal de Educação, o Plano de Desenvolvimento da Educação, o Projeto Político Pedagógico da Secretaria Municipal e das próprias escolas pertencentes à rede pública municipal.

Os achados decorrentes dos estudos anteriormente realizados, sinalizando para a transversalização das políticas educacionais no modus operandi, tanto no âmbito da Secretaria de Educação quanto no contexto das escolas, foram corroborados quando, em 2010, nosso grupo de pesquisa foi procurado por profissionais que atuavam na Secretaria de Educação, os quais nos mobilizaram a auxiliar na construção de uma plataforma de formação que contemplasse as reais demandas formativas dos profissionais da educação da rede pública municipal. Podemos dizer que o movimento constitutivo da atual Política de Valorização e Qualificação dos Profissionais da Educação no munícipio teve sua gênese e ganhou força a partir desse encontro, porque entendíamos que não bastaria uma plataforma formativa se não houvesse proposição e consolidação de uma política pública que legitimasse e viabilizasse sua consolidação. Assim, neste ano, iniciamos a construção de uma pesquisa-ação colaborativa focando o processo constitutivo das políticas, sendo a justificativa pela opção dos pesquisadores por essa abordagem investigativa já apresentada nas seções antecedentes.

\section{Participantes do estudo}

O estudo tem como protagonistas os profissionais da educação que atuam na Secretaria de Educação e compõem a Diretoria de Educação Infantil, a Diretoria Pedagógica, a Diretoria de Ensino Fundamental e a Diretoria de Educação Inclusiva. Esses profissionais são os responsáveis em mobilizar as equipes diretivas das escolas (direção, vice-direção, supervisão e orientação educacional) e os professores para a construção coletiva e participativa das principais políticas educacionais do munícipio, sendo esse o contexto indutor do delineamento e da proposição de tais políticas. 
Entre os anos de 2010 e 2012, mantivemos um grupo composto por seis profissionais integrantes das Diretorias anteriormente citadas. Desses seis profissionais, cinco professoras são servidoras públicas concursadas, e uma delas atua na modalidade de cargo de confiança. Em termos de formação acadêmica, duas professoras possuem o título de Mestre em Educação e as demais são especialistas. Uma das professoras já atuava na Secretaria desde o ano de 2006, e as demais ingressaram na gestão no ano de 2009. A gestão participativa e transparente é o mote do ideário político-pedagógico do governo municipal. Esse ideário tem contribuído para a discussão e a construção coletiva de dispositivos orientadores da ação educativa no âmbito da rede pública e sua articulação com a Universidade. Essa articulação tem se constituído em um diferencial para ambas as instituições, considerando-se que a pesquisa, ao propiciar a análise reflexiva, a construção e a socialização do conhecimento, também contribrui para repensar a educação no munícipio.

\section{Instrumentos de coleta de dados e etapas constituintes da abordagem metodológica}

No decorrer da pesquisa, foram utilizados para a coleta de dados: a análise documental (LAVILLE; DIONNE, 1999; PIMENTEL, 2001; GIL, 2010; PÁDUA, 2011); o questionário (LAVILLE; DIONNE, 1999; MARCONI; LAKATOS, 2006); os registros de observações dos encontros formativos realizados no Diário de Campo (BOGDAN; BIKLEN, 1994); e a entrevista semiestruturada (MAY, 2004). Destacamos que tais instrumentos, comumente adotados em outras abordagens investigativas de cunho qualitativo, na pesquisaação colaborativa, são utilizados pelos pesquisadores de forma mais interativa, dinâmica e participativa visando superar algumas limitações presentes em cada um deles.

Tendo presente as peculiaridades da abordagem metodológica adotada nesta investigação, com base no que sugerem Kemmis e Mc'Taggart (1992), apresentamos, na sequência, a sistematização das etapas constituintes do plano de trabalho.

- $1^{\mathrm{a}}$ Etapa: Diagnóstico-reconhecimento e fortalecimento de identidade de grupo

O trabalho com o coletivo de participantes do estudo é um dos aspectos fundamentais na pesquisa-ação. Dessa forma, ações são postas em prática para viabilizar o processo de pesquisa diagnóstica que compõe essa primeira etapa. Para tanto, aplicamos um questionário a fim de caracterizar os participantes e 
identificar suas concepções sobre a educação, o conhecimento, o ensino e a aprendizagem, a formação docente e, também, suas próprias demandas formativas para o exercício de sua função no âmbito da Secretaria.

No início de 2013, o grupo de participantes do estudo sofreu algumas alterações devido ao fato de ter ocorrido mudanças em termos de cargos e atribuições no âmbito da Secretaria de Educação. Somos sabedores que, em uma Secretaria Municipal de Educação, as mudanças em termos de gestão são constantes o que, no nosso entender, provocam rupturas nos processos, sejam eles de cunho mais administrativo ou pedagógico, na constituição e na consolidação de comunidades de aprendizagem. Para minimizar essa ruptura, um novo diagnóstico com os entrantes e a retomada de pressupostos centrais foram necessários, a fim de assegurarmos a continuidade e o avanço nas reflexões e nas construções consolidadas. Entretanto, o alinhamento em termos de ideários, de propostas e de perspectivas tem se constituído um grande desafio para todos os participantes.

\section{- $2^{\text {a }}$ Etapa: Planejamento das ações}

A proposição de espaços formativos ganha centralidade nesta segunda etapa. Essa abordagem está circunscrita pela visão de que a educação correlaciona-se com um processo amplo de formação e de humanização. Assim sendo, consideramos a formação como parte essencial do processo investigativo (FRANCO, M. A. S., 2005; PIMENTA, 2005; MONCEAU, 2005; ZEICHNER; DINIZ-PEREIRA, 2005; ELLIOT, 2000).

A pesquisa-ação pode agregar valor no processo de formação, sem, no entanto, ser reduzida a ela, pois possibilita a intervenção e a transformação da realidade por parte dos envolvidos. A ação teórica emerge como processo social, humano e humanizador, por meio do qual podemos compreender melhor a nós mesmos e ao mundo no qual vivemos. Nesse viés, “[...] o fato de teorizar forma parte do processo dialético de autotransformação e de mudança social: o processo através do qual os indivíduos reconstroem a si mesmos e, ao mesmo tempo, reconstroem sua vida social" (CARR, 1996, p. 15).

Dessa forma, no decorrer da pesquisa, foram realizados encontros individuais e encontros formativos com os protagonistas de nosso estudo, cujos focos temáticos foram detectados durante a realização da primeira etapa da pesquisa. Assim, em um movimento dialético e dialógico, trabalhamos na perspectiva de formação com os profissisonais da Secretaria, tendo em vista o empoderamento na função exercida e a sua constituição como partícipes e mediadores nos processos de formação dos outros profissionais da educação da rede. Com base na caracterização que realizamos das professoras, ficou evidente que, dentre as seis, somente uma tinha experiência de atuação na Secretaria 
Municipal. As demais foram indicadas a assumir a Secretaria com base no desempenho em suas escolas. Ora, todos temos ciência de que são contextos e âmbitos de atuação diferenciados, o que requer, das professoras, além de um período de adaptação à nova função, também um conjunto de conhecimentos e de procedimentos relacionados à gestão de um macrosistema. Assim, de forma interseccionada, foi se constituindo um processo formativo contemplando a formação do formador de outros formadores.

Nos encontros formativos quinzenais com os profissionais da Secretaria, os principais tópicos abordados, além dos fundamentos teórico-metodológicos da pesquisa ação-colaborativa, foram os dispositivos legais orientadores da ação educativa na Educação Básica (Lei de Diretrizes e Bases da Educação Nacional (BRASIL, 1996); Resolução no 2/98, (CNE/CEB, 1998) e Resolução no 3/2005 (CNE/CEB, 2005); Parecer no 6/2005 (CNE/CEB, 2005); Parecer no 18/2005 (CNE/CEB, 2005)); a formação docente, o protagonismo e a autonomia docente; a Epistemologia da prática, o professor e a escola reflexiva. Para tanto, valemo-nos dos pressupostos de autores tais como: Alarcão (1996, 2001), Schön (1992, 2000), Contreras (2002), Tardif (2010) e Zeichner (1993), dentre outros. Nesse sentido, conforme aponta Roldão (2007, p. 98), é necessário “o saberfazerer, saber como fazer, e saber por que se far".

Nessa etapa, os profissionais da Secretaria de Educação e os pesquisadores construíram e aplicaram um questionário para a identificação das demandas formativas dos professores e dos gestores da rede. A partir dos dados coletados, foram delineados os contéudos de cada formação, quanto à extensão, os quais estruturam a oferta de Cursos de Extensão para os professores, supervisores e orientadores; e para os gestores (direção e vice-direção) das escolas de Educação Infantil e do Ensino Fundamental.

- $3^{a}$ Etapa: Aplicação de estratégias de ação, processo de observaçãoregistro e avaliação

Nessa etapa, deu-se início aos Cursos de Extensão que foram realizados na Universidade. Cada ação formativa teve o acompanhamento sistemático de um dos profissionais da Secretaria participantes de nossa investigação com a função de observar, interagir e registrar dimensões e aspectos importantes observados na formação. Mediante a avaliação das formações realizadas, expressas nas fichas de avaliação, avaliadas positivamente tanto pelos participantes dos cursos quanto pela equipe da pesquisa que acompanhou, fomos mobilizados a avançar na proposta de formação. Nosso ideário inicial, para o qual fomos mobilizados, era a construção de uma plataforma formativa composta por outras modalidades além da extensão. Nesse ponto, com base nas expectativas dos profissionais da 
rede, o movimento realizado pelo coletivo de profissionais da rede e com a sustentação do Secretário de Educação, o governo municipal foi mobilizado a firmar uma Política Municipal, a qual contemplou, também, a aprovação do Plano de Carreira. Assim, surgiu a plataforma formativa denominada Programa de formação continuada escola em movimento saberes e fazeres em cena, subsidiada financeiramente, de forma integral, pela Prefeitura Municipal. O Programa de formação está estruturado nos seguintes ciclos formativos: a) Ciclo Formativo I: ações voltadas à extensão; b) Ciclo Formativo II: curso de especialização, cuja matriz curricular é construída coletivamente entre a Universidade e a Secretaria de Educação, com base nas demandas formativas e nas necessidades educacionais da rede pública municipal; c) Ciclo Formativo III: Mestrado em Educação; e d) Ciclo Formativo IV: Doutorado em Educação. Com exceção das ações formativas em relação à extensão, em todas as demais, é obrigatória a participação em processo seletivo via edital público.

Em sua primeira edição 2010-2013, o Programa contemplou ações formativas, no que concerne à extensão, para 84 diretores e vice-diretores, 22 orientadores, 22 supervisores e 120 professores que exercem a docência no Bloco de Alfabetização (três primeiros anos do Ensino Fundamental). Paralelamente, a Prefeitura Municipal deu 84 bolsas integrais para professores da rede realizarem o Curso de Pós-graduação lato sensu, desenhado coletivamente e em parceria com os envolvidos (Ação Educativa no Ensino Fundamental) e 30 bolsas para os professores da Educação Infantil (Ação Educativa na Educação Infantil) focalizando a realidade educacional das escolas municipais da cidade. Como produtos desses cursos, são 114 monografias, realizadas e direcionadas, exclusivamente, para a problematização da educação municipal.

Também, no ano de 2011, foram destinadas 10 bolsas integrais para professores da rede que foram aprovados no processo seletivo do Curso de Mestrado em Educação. Todos os professores em formação continuada, tanto na pós-graduação lato sensu quanto strictu sensu realizaram suas monografias e dissertações, respectivamente, focando uma temática relacionada à educação municipal. Fruto de descontinuidades e rupturas decorrentes de posições dogmáticas e lutas de poder, a consolidação dessa política atinge seu ápice no ano de 2013, por meio do compromisso da gestão municipal com a oferta de mais oitenta bolsas integrais para cursos de pós-graduação lato sensu (40 bolsas para o curso de especialização em Educação Inclusiva e 40 bolsas para o curso de especialização em Supervisão e Orientação Educacional) e dez bolsas para a pós-graduação stricto sensu (Mestrado em Educação). Com a aprovação do Doutorado em Educação, está previsto bolsas para os professores continuarem sua trajetória formativa. 
- $4^{a}$ Etapa: Reflexão e reorganização

Nessa etapa, ocorre o processo de re-elaboração das estratégias de ação, garantindo, dessa forma, o movimento espiralado próprio da metodologia da pesquisa-ação, o qual oportuniza a continuidade do processo investigativo, seja aprofundando a temática central que originou o estudo seja abrindo novas frentes temáticas. Nela, os pesquisadores e os participantes revisitam a análise, a interpretação e a elaboração de conclusões de forma pormenorizada a partir dos registros, dos documentos, dos arquivos, etc., produzidos durante as etapas anteriores. É o momento dedicado a revisar todo o processo, procurando localizar os avanços, os desafios, as lacunas e as limitações vivenciadas tanto no processo de condução da pesquisa-ação quanto nas ações assumidas pelo coletivo. Na nossa pesquisa, a quarta etapa será concluída em 2014. Para essa conclusão, estamos realizando encontros cuja centralidade da discussão dar-se-á a partir da análise, da avaliação e da organização dos registros produzidos pelos pesquisadores e pelos partipantes do estudo. Com base nisso, serão feitas análises, interpretações e proposições para desencadear outra fase da pesquisa, cuja dinâmica traduz-se em um movimento espiralado, tal como idealizado por Lewin (2006). Esperamos, nessa etapa, contar com a contribuição de dois pesquisadores colaboradores estrangeiros com o qual mantemos interlocuções no decorrer deste estudo, com o objetivo de possibilitar uma leitura crítica do processo da pesquisa, assim como de intercâmbio entre experiências de pesquisa-ação colaborativa.

\section{Técnica de Análise dos dados}

A análise dos dados coletados foi realizada por meio da Técnica de Análise de Conteúdo proposta por Bardin (1988). Tal análise integra um conjunto de técnicas que possibilitam, por intermédio de procedimentos sistemáticos de descrição do conteúdo, a realização de inferências acerca da produção e/ou da recepção de determinada mensagem (BARDIN, 1988). Em relação ao processo da análise de conteúdo, Bardin apresenta três etapas: pré-análise; exploração do material; e tratamento dos resultados, inferência e interpretação.

a) Fase de pré-análise: $\mathrm{Na}$ fase de pré-análise, realizamos o que Bardin (1988) denomina de leitura flutuante, ou seja, uma leitura geral estabelecendo o primeiro contato com os conteúdos coletados, tendo-se presente as seguintes regras: i) Exaustividade: consideração de todos os elementos presentes nos conteúdos; ii) Representatividade: seleção daqueles elementos presentes nos conteúdos que são representativos em relação ao que nos propomos investigar. É necessário priorizar aqueles que possuem maior significado e consistência com relação aos objetivos do estudo; iii) Homogeneidade: os conteúdos coletados serão agrupados considerando-se a estreita relação com a categoria temática; 
iv) Pertinência: os conteúdos selecionados deverão estar adequados, em termos de informação, e corresponder aos objetivos e questões norteadoras delineadas.

b) Fase de exploração: Nessa fase, definimos as categorias. Optamos por utilizar como unidade de registro o tema, por ser ele considerado, por Bardin (1988), o mais adequado para o tipo de estudo proposto. Franco, M. L. P. B. (2005, p. 39) reafirma essa ideia, destacando que essa unidade de registro é a mais indicada para ser utilizada em estudos que envolvam "[...] representações sociais, opiniões, expectativas, valores, conceitos, atitudes e crenças". A categorização, conforme explica Franco, M. L. P. B. (2005, p. 57), “[...] é uma operação de classificação de elementos constitutivos de um conjunto, por diferenciação seguida de um reagrupamento baseado em analogias, a partir de critérios definidos".

c) Fase de tratamento dos resultados, inferência e interpretação: Nessa fase, as categorias temáticas foram submetidas a operações de decomposição de cada conteúdo identificado nos intrumentos de coleta de dados utilizados. A partir das temáticas captadas na análise do material, procedemos à interpretação dos dados, procurando não perder a visão de conjunto, considerando elementos contextuais relevantes e identificando possíveis lacunas, contradições ou avanços.

\section{Processos constitutivos das políticas públicas municipais desde a perspectiva de uma pesquisa-ação colaborativa: avanços, desafios e lacunas}

Entendemos que, nos processos constitutivos das políticas, é preciso ter presente que os profissionais da educação possuem saberes (TARDIF, 2010) e são capazes de produzir conhecimentos. Tal compreensão configura-se em uma das possibilidades para a superação da controversa oposição entre teoria e prática (BECKER, 1993), pois demonstra, sob a ótica da educação escolar, a necessária unidade e a mútua dependência dessas duas instâncias.

Se, por um lado, a consideração das dimensões políticas, econômicas, socioculturais e educacionais é fundamental para a compreensão sobre como se constituem as políticas educacionais no município, foco de nossa investigação, por outro, tais dimensões constituem-se no próprio objeto de estudo da política educacional. Tais políticas não estão descoladas de um conhecimento histórico que se consolidou paulatinamente e nem de um plano político do governo instaurado, que se pauta em determinados princípios educacionais.

No decorrer da pesquisa e nela imersos, assumimos a posição de tradutores e de mediadores das múltiplas vozes advindas dos diversos atores envolvidos na ação educativa, no âmbito da Secretaria Municipal de Educação. Assim, deparamo-nos com um cenário demarcado por conteúdos polissêmicos e, por vezes, 
até antagônicos, o que exigiu do coletivo esforços para ressignificar, interpretar, analisar, contextualizar e construir uma síntese compreendida em uma perspectiva dialética. A busca pela produção de uma ação-reflexão crítica com os profissionais da educação, com vistas à construção de ações colaborativas pela via de um processo de investigação-formação, suscitou a necessidade de formação.

A formação foi essencial no decorrer da pesquisa, considerando-se a necessidade de reflexão acerca de alguns conceitos que transversalizam o bojo estruturante de várias políticas educacionais no muncípio, a saber: o sentido de investigação-formação; o conhecimento pedagógico; a educação como práxis; o protagonismo e a autonomia docente; o professor e a escola reflexiva.

Fundamentados em Carr (1996), entendemos que o que caracteriza a práxis é que ela consiste em uma forma de ação reflexiva, que pode criticar e transformar a teoria que a rege. Nem a teoria, nem a prática gozam de proeminência: cada uma modifica e revisa continuamente a outra. Por isso, podemos entender a prática educativa como práxis pedagógica. Portanto, por práxis pedagógica entendemos o agir que presentifica, sistematiza e implementa um projeto de educação. Toda prática educativa recorre a uma noção de educação e a uma teoria educacional, das quais ela pode extrair compreensões amplas acerca do mundo, da pessoa humana e da sociedade.

Ao trazer à tona as concepções dos participantes do estudo, deparamonos com certo ecletismo teórico e com visões, em alguns casos, até dogmáticas, oriundas de tendências político-partidárias. Não podemos esquecer que, geralmente, aqueles que estão à frente da gestão em uma Secretaria de Educação, representam, quase que diretamente, o(s) partido(s) político(s) que governa. Esse foi um dos desafios encontrados, pois nem sempre foi viável a construção de uma síntese dialética necessária para o avanço em termos de proposição de ideias. Outro aspecto a ressaltar é que, ao nos debruçarmos sobre a análise coletiva dos dispositivos existentes no âmbito da Secretaria de Educação, constatamos a precariedade dos registros existentes e da escassez de informações sistematizadas de forma orgânica. Nesse ponto, outra contribuição do estudo foi a de auxiliar os gestores e suas equipes na organização e na sistematização de registros essenciais ao processo educativo.

Ora, nesse contexto dos encontros formativos, a abordagem teóricometodológica adotada constituiu-se em elemento viabilizador e propulsor do diálogo construtivo pautado pelo respeito à pluralidade (HERMANN, 2001) o qual foi um dos principais responsáveis e mobilizadores da ação reflexiva, contribuindo, assim, para a formulação de políticas direcionadas à Valorização e Qualificação dos Profissionais da Educação; a (re)vitalização da Política de Monitoramento da Qualidade da Educação Municipal; a (re)vitalização das Diretrizes norteadoras do Bloco de Alfabetização e dos dispositivos legais, 
tais como: o Plano Municipal de Educação, o Plano de Desenvolvimento da Educação, o Projeto Político-Peagógico da Secretaria, dentre outros.

A ação formativa continuada com os gestores e as equipes da Secretaria de Educação contribuiu para o empoderamento desses atores, fortalecendo-os perante a própria rede de ensino. A partir e concomitamente a tal formação, foram adotadas estratégias formativas as quais contemplavam, também, espaços e tempos para a construção coletiva da política de formação continuada. Dessa forma, os protagonistas deste estudo passaram a se constituir como pesquisadores de sua própria prática.

A construção e a consolidação de comunidades de aprendizagem, compreendida sob a égide de grupos que partilham e constroem cumplicidades científicas, epistemológicas e pedagógicas (BRYDON-MILLER; MAGUIRE, 2009), requer um espaço temporal que, muitas vezes, difere do tempo de uma determinada pesquisa. Talvez aqui resida uma das maiores contribuições da pesquisa-ação colaborativa, na medida em que a concepção de movimento espiralado viabiliza a continuidade do processo investigativo. Assim, nesse movimento espiralado reflexivo que contempla o empoderamento dos atores, o (re)planejamento, a ação, a observação e a reflexão, com base nas relações colaborativas, vai consolidando a ideia de comunidade de aprendizagem, em que os participantes são compreendidos, também, como pesquisadores e coresponsáveis. Certamente esse entendimento e essa construção paulatina que estão experienciando junto aos profissionais da educação da Secretaria Municipal de Educação tem sido um diferencial para que eles conduzam os processos constitutivos de (re)vitalização ou criação de políticas educacionais.

Em termos de lacunas e de desafios encontrados nos processos constitutivos das políticas educionais, mais precisamente no caso em pauta, foram a transitoriedade e as constantes alterações dos gestores no âmbito da Secretaria de Educação. Essas alterações, que no últimos dois anos se acentuaram, de certa forma comprometeram a continuidade dos processos até então instaurados, requerendo do grupo uma constante readequação. As rupturas e as descontinuidades em termos de (re)composição do grupo requerem, por vezes, um constante reiniciar.

Quanto às limitações do estudo, é possível destacar a questão temporal da pesquisa, pois, quando almejamos tranformações, é necessário um processo longo e constante de reflexão-ação-crítica. Sabemos que os impactos decorrentes da pesquisa-ação não são imediatos, mas expectáveis com o decorrer do tempo. Como anunciamos na introdução deste texto, desde o ano de 2006, estamos inseridos no locus investigativo. Algumas transformações já conseguimos vislumbrar, assim como alguns retrocessos. Ficam alguns questionamentos sobre 
os quais ainda desejamos nos debruçar acerca dos resultados decorrentes das políticas construídas e delineadas coletivamente no que tange a sua efetivação cotidiana. Também fica a questão quanto à representatividade das vozes que as constituíram no contexto macro: se estas foram fruto de uma intensa participação em que preponderou a ação-reflexão ou de apenas concordância. O olhar e a avaliação que possuímos perpassam pelo olhar e pela avaliação dos protagonistas que lideraram essas ações com o coletivo de professores da rede. Portanto, como o estudo focalizou o grupo de gestores da Secretaria e suas equipes, e a ação realizada por estes não foi acompanhada por meio de um processo investigativo, entendemos que a resposta a algumas questões requer adentrar em outra fase da pesquisa-ação, tematizando tais questões até então não respondidas.

\section{Considerações finais}

Entendemos que a proposta de uma pesquisa-ação participativa com foco na construção de políticas educacionais para um contexto específico, como o caso do município em tela, consiste em uma tentativa de superação das idiossincrasias e dos problemas metodológicos e epistemológicos que normalmente os pesquisadores defrontam-se no campo educacional. Percebemos que o caso por nós abordado contempla uma modalidade de investigação científica que parte da realidade concreta dos sujeitos participantes da ação, envolvendo pesquisadores e pesquisados na busca por soluções que melhorem as condições educacionais no referido município. Tal procedimento explicita uma forma de aproximar a teoria da prática. Explicita, também, uma epistemologia que "parte da realidade e contribui com ela" (TELLO, 2012a, p. 65).

Em relação à metodologia participativa, demarcada pela pesquisa-ação colaborativa, cumpre dizer que a consideramos um claro exemplo da possibilidade de construção da participação e da democracia. Trata-se de um espaço que congrega a possibilidade de que cada participante do processo de investigação-ação seja capaz de aprender, de construir e de reconstruir os componentes estruturais do próprio mundo, resignificando experiências e conceitos e, ao mesmo tempo, constituindo um coletivo que sonha e age conjuntamente em prol da construção de um projeto coletivo comum.

Os achados emergentes do estudo sinalizam para a relevância da pesquisa-ação colaborativa compreendida como postura epistemológica, metodológica e política, pois por meio dela estamos consolidando, na qualidade de grupo de pesquisa, uma trajetória coletiva que contempla a ação-reflexão e a intervenção crítica no contexto educacional local. Esse movimento dialético e dialógico permite-nos, como pesquisadores, uma ação investigativa e formativa com (e não para ou sobre) os profissionais da educação da educação básica do município. 
Permite-nos, também, como formadores, sermos protagonistas nos processos constitutivos naõ só das Políticas Educacionais Municipais mas também dos seus modos de efeitvação no cotidiano.

Por fim, conforme salientado, ao final do ano de 2014, procederemos à última etapa da pesquisa, etapa na qual ocorrerá o processo de reelaboração das estratégias de ação, garantindo, dessa forma, o movimento espiralado próprio da metodologia da pesquisa-ação. Almejamos que as reflexões apresentadas no decorrer deste texto possam contribuir para o avanço das discussões atinentes às políticas educacionais e à pesquisa-ação colaborativa como postura epistemológica, metodológica e política.

\section{Referências}

ALARCÃO, I. Escola reflexiva e nova racionalidade. Porto Alegre: Artmed, 2001.

AZEVEDO, J. M. L. de; AGUIAR, M. Â. A produção do conhecimento sobre a política educacional no Brasil: um olhar a partir da ANPED. Educação \& Sociedade, Campinas, v. 22, n. 77, p. 49-70, dez. 2001. DOI: 10.1590/S0101-73302001000400004

BARDIN, L. Análise de conteúdo. Tradução de Luís Antero Reto e Augusto Pinheiro. Lisboa: Edições 70, 1988.

BECKER, F. A epistemologia do professor: o cotidiano da escola. Petrópolis: Vozes, 1993.

BOGDAN, R. C.; BIKLEN, S. K. Investigação qualitativa em educação. Porto: Porto, 1994.

BOURDIEU, P. Os usos sociais da ciência: por uma sociologia clínica do campo científico. São Paulo: Editora UNESP, 2004.

BRASIL. Lei $\mathbf{n}^{\mathbf{0}}$ 9.394, de 20 de dezembro de 1996. Estabelece as diretrizes e bases da educação nacional. Brasília: Ministério da Educação, 1996. Disponível em: < http://www. planalto.gov.br/ccivil_03/Leis/L9394.htm>. Acesso em: 15 ago. 2010.

BRASIL. Plano de Desenvolvimento da Educação. Brasilia: Ministério da Educação, 2007. Disponível em: <http://portal.mec.gov.br/arquivos/livro/index.htm>. Acesso em: 15 ago. 2010.

BRYDON-MILLER, M.; MAGUIRE, P. Participatory action research: contributions to the development of practitioner inquiry in education. Educational Action Research, v. 17, n. 1, p. 79-93, 2009. DOI: $10.1080 / 09650790802667469$

CARR, W. Una teoría para la educación: hacia una investigación educativa crítica. Madrid: Morata, 1996.

CARR, W.; KEMMIS, S. Teoría crítica de la enseñanza: la investigación-acción en la formación del profesorado. Tradução de J. A. Bravo. Barcelona: Martínez Roca, 1988.

CHARLOT, B. A pesquisa educacional entre conhecimentos, políticas e práticas: especificidades e desafios de uma área do saber. Revista Brasileira de Educação, Rio de Janeiro, v. 11, n. 31, p. 07-18, jan./abr. 2006. DOI: 10.1590/S1413-24782006000100002 
CNE/CEB. Conselho Nacional de Educação/Câmara de Educação Básica. Resolução $\mathbf{n}^{\mathbf{0}}$ 2/98, de 7 de abril de 1998. Institui as Diretrizes Curriculares Nacionais para o Ensino Fundamental. Brasília, 1998.

CNE/CEB. Conselho Nacional de Educação/Câmara de Educação Básica. Parecer $\mathbf{n}^{\mathbf{o}}$ 6/2005, de 8 de junho de 2005. Estabelece normas nacionais para a ampliação do ensino fundamental para nove anos de duração. Brasília, 2005.

CNE/CEB. Conselho Nacional de Educação/Câmara de Educação Básica. Parecer $\mathbf{n}^{\mathbf{o}}$ 18/2005, de 15 de setembro de 2005. Orienta a matrícula das crianças de 6 (seis) anos de idade no ensino fundamental obrigatório, em atendimento à Lei no 11.114 , de 16 de maio de 2005. Brasília, 2005.

CNE/CEB. Conselho Nacional de Educação/Câmara de Educação Básica. Resolução $\mathbf{n}^{\mathbf{o}} \mathbf{3} / \mathbf{2 0 0 5}$, de 3 de agosto de 2005. Define normas nacionais para a ampliação do ensino fundamental para nove anos de duração. Brasília, 2005.

CONTRERAS, J. D. A autonomia de professores. São Paulo: Cortez, 2002.

ELLIOTT, J. El cambio educativo desde la investigación-acción. 3. ed. Tradução de Pablo Manzano. Madrid: Morata, 2000.

FRANCO, M. A. S. Pedagogia da pesquisa ação. Educação e Pesquisa, São Paulo, v. 31, n. 3, p. 483-502, dez. 2005. DOI: 10.1590/S1517-97022005000300011

FRANCO, M. L. P. B. Análise de conteúdo. 2. ed. Brasília: Liber Livro, 2005.

GADAMER, H. G. Hermenêutica em retrospectiva: a virada hermenêutica. Petrópolis: Vozes, 2007.

GIL, A. C. C. Método e técnicas de pesquisa social. São Paulo: Atlas, 2010.

HABERMAS, J. O discurso filosófico da modernidade: doze lições. São Paulo: Martins Fontes, 2002a.

HABERMAS, J. Agir comunicativo e razão destranscendentalizada. Rio de Janeiro: Tempo Brasileiro, 2002b.

HERMANN, N. Pluralidade e ética em educação. Rio de Janeiro: DP\&A, 2001.

KEMMIS, S.; MCTAGGART, R. Cómo planificar la investigación-acción. Barcelona: Laertes Ediciones, 1992.

LAVILLE, C.; DIONNE, J. A construção do saber: manual de metodologia de pesquisa em ciências humanas. Porto Alegre: Artes Médicas Sul Ltda., 1999.

LEWIN, K. La investigación-acción y los problemas de las minorías. In: SALAZAR, M. C. (Org.). La investigación-acción participativa: inicios y desarrollos. Tradução de María Cristina Salazar. Madrid: Editorial Popular, 2006. p. 15-25.

MARCONI, M. A.; LAKATOS, E. M. Técnicas de pesquisa: planejamento e execução de pesquisas, amostragens e técnicas de pesquisa, elaboração, análise e interpretação dos dados. São Paulo: Atlas, 2006.

MAY, T. Pesquisa social: questões, métodos e processos. 3. ed. Porto Alegre: Artmed, 2004. MIRANDA, M. G.; RESENDE, A. C. A. Sobre a pesquisa-ação na educação e as armadilhas do praticismo. Revista Brasileira de Educação, Rio de Janeiro, v. 11, n. 33, p. 511-518, set./ dez. 2006. DOI: 10.1590/S1413-24782006000300011 
MONCEAU, G. Transformar as práticas para conhecê-las: pesquisa-ação e profissionalização docente. Educação e Pesquisa, São Paulo, v. 31, n. 3, p. 467-482, set./dez. 2005. DOI: 10.1590/S1517-97022005000300010

PÁDUA, E. M. M. Metodologia de pesquisa: abordagem teórico-prática. Campinas: Papirus, 2011.

PIMENTA, S. G. Pesquisa-ação crítico-colaborativa: construindo seu significado a partir de experiências com a formação docente. Educação e Pesquisa, São Paulo, v. 31, n. 3, p. 521 539, set./dez. 2005. DOI: 10.1590/S1517-97022005000300013

PIMENTEL, A. O método da análise documental: seu uso numa pesquisa histórica. Cadernos de Pesquisa, São Paulo, n. 114, p.179-195, nov. 2001. DOI: 10.1590/S010015742001000300008

ROLDÃO, M. do C. Função docente: natureza e construção do conhecimento profissional. Revista Brasileira de Educação, Rio de Janeiro, v. 12, n. 34, p. 94-103, jan./abr. 2007. DOI: 10.1590/S1413-24782007000100008

SHÖN, D. A. Formar professores como profissionais reflexivos. In: NÓVOA, A. (Coord.). Os professores e sua formação. Lisboa: Dom Quixote, 1992. p. 77-91.

SHÖN, D. A. Educando o profissional reflexivo, um novo design para o ensino e a aprendizagem. Artmed: Porto Alegre, 2000.

TARDIF, M. Saberes docentes e formação profissional. Petrópolis: Vozes, 2010.

TELLO, C. G. Las epistemologías de la política educativa como enfoque y la vigilancia y el posicionamiento epistemológico del investigador. Práxis Educativa, Ponta Grossa, v. 7, n. 1, p. 53-68, jan./jul. 2012a. DOI: 10.5212 /PraxEduc.v.7i1.0003

TELLO, C. G. Las epistemologías de la política educativa en Latinoamérica: notas históricas y epistemológicas sobre el campo. Revista Espaço Pedagógico, Passo Fundo, v. 19, n. 2, p. 282-299, jul./dez. 2012b.

ZEICHNER, K. M. A Formação Reflexiva de Professores, Idéias e Práticas. EDUCA, Lisboa , 1993.

ZEICHNER, K. M. Para além da divisão entre professor-pesquisador e pesquisador acadêmico. In: GERALDI, C. M.; FIORENTINI, D.; PEREIRA, E. M. (Orgs.). Cartografia do trabalho docente: professor(a)-pesquisador(a). Campinas: Mercado de Letras, 1998. p. 207-236.

ZEICHNER, K. M.; DINIZ-PEREIRA, J. E. Pesquisa dos educadores e formação docente voltada para a transformação social. Cadernos de Pesquisa, São Paulo, v. 35, n. 125, p. 6380, maio/ago. 2005. DOI: 10.1590/S0100-15742005000200005

Recebido em 30/11/2013

Versão final recebida em 31/03/2014

Aceito em 07/04/2014 